\title{
Research on the Concentration Prediction of Nitrogen in Red Tide Based on an Optimal Grey Verhulst Model
}

\author{
Xiaomei Hu, ${ }^{1}$ Yubin Wang, ${ }^{1}$ Yue Yu, ${ }^{1}$ Dong Wang, ${ }^{1}$ and Yuan Tian ${ }^{2}$ \\ ${ }^{1}$ The Key Laboratory of Intelligent Manufacturing and Robotics, School of Mechatronic Engineering and Automation, \\ Shanghai University, Mailbox 232, No. 149 Yanchang Road, Shanghai 200072, China \\ ${ }^{2}$ Department of Mechanical Engineering, College of Engineering, University of Michigan, Ann Arbor, MI 48105, USA
}

Correspondence should be addressed to Xiaomei Hu; sufeimasohxm@163.com

Received 21 March 2016; Revised 2 August 2016; Accepted 15 August 2016

Academic Editor: Rosana Rodriguez-Lopez

Copyright (C) 2016 Xiaomei Hu et al. This is an open access article distributed under the Creative Commons Attribution License, which permits unrestricted use, distribution, and reproduction in any medium, provided the original work is properly cited.

\begin{abstract}
In order to reduce the harm of red tide to marine ecological balance, marine fisheries, aquatic resources, and human health, an optimal Grey Verhulst model is proposed to predict the concentration of nitrogen in seawater, which is the key factor in red tide. The Grey Verhulst model is established according to the existing concentration data series of nitrogen in seawater, which is then optimized based on background value and time response formula to predict the future changes in the nitrogen concentration in seawater. Finally, the accuracy of the model is tested by the posterior test. The results show that the prediction value based on the optimal Grey Verhulst model is in good agreement with the measured nitrogen concentration in seawater, which proves the effectiveness of the optimal Grey Verhulst model in the forecast of red tide.
\end{abstract}

\section{Introduction}

With the population expansion, land resources are becoming more and more precious, which leads to the shortage of material resources and the crisis of energy. The development of marine resources has become an effective way to relieve the pressure of resources and environment in the 21st century. With rapid development of marine resources, a variety of marine disasters follow as a result. In particular, the occurrence of red tide as well as the harm caused by it is frequently increasing [1]. Many researches have shown that the eutrophication of the seawater is the primary condition of the occurrence of red tide. The increase of nitrogen, phosphorus, and other nutrient salts in seawater greatly promotes the eutrophication of seawater [2]. Moreover, the nitrogen concentration in seawater is regarded as a key factor to predict the occurrence of red tide. Measured results have shown that the change of the nitrogen concentration in seawater is not monotonous.

Through the analysis of Grey system model and traditional Verhulst model, it is found that Grey system model is suitable to describe the monotonous change process, but it can be used in small sample data as well $[3,4]$. In contrast, traditional Verhulst model is suitable for nonmonotonous data, but large samples are required [5]. In light of the characteristics of the change of the nitrogen concentration in seawater, Grey Verhulst model is applied to predict the nitrogen concentration in seawater. In Grey Verhulst model, an accumulation result of the original data is used to expand the scope of the application of the traditional Verhulst model $[6,7]$. Therefore, Grey Verhulst model has been widely used in recent years [8-11].

In order to improve the accuracy of the prediction, an optimal Grey Verhulst model is proposed to predict the nitrogen concentration in seawater. The experimental results show its high precision and small error compared with other models [12], a testament to the effectiveness of the optimal Grey Verhulst model. So the optimal Grey Verhulst model can be applied to forecast red tide.

\section{Related Work}

2.1. Research on Red Tide Disaster. Red tide is an abnormal ecological phenomenon which is caused by fulminating 
proliferation or accumulation of plankton in seawater [13]. According to statistics, the frequency and the cumulative occurrence area of red tide are both increasing year by year.

Although the mechanism of the occurrence of red tide has not been determined yet, the main reasons that increase the frequency of red tide are widely recognized as follows [14]:

(1) More and more eutrophic seawater

(2) The increase of the utilization and the development of coastal water, such as the development of aquaculture, which leads to marine pollution

(3) The increasing marine traffic, which is considered to expand the distribution of some harmful algae

(4) Abnormal climate events, such as Nino and Southern Oscillation phenomenon

(5) Decreasing efforts in the marine environmental protection and careless attitude towards the red tide

A large number of studies have shown that the occurrence of red tide is most strongly associated with seawater eutrophication [2]. Therefore, the research on the forecast of the concentration of nitrogen in seawater has great significance in the prediction of red tide disaster.

2.2. Grey Verhulst Model. Grey system theory was established and developed by Professor Julong Deng at the beginning of 1980s, which has been successfully applied in industrial, agricultural, economic, and other fields, solving many practical problems in production and scientific research. Specifically, Grey system theory is mainly used in small sample monotonous data. Grey system theory can effectively deal with incomplete and uncertain information. The Grey model (GM) is the core of Grey system theory, which collects available data to obtain the internal regularity without using any assumptions. The forecasting accuracy is related to the sample number $n$ in GM. However, Gray model always needs to be combined with other methods to optimize the model, which can increase the accuracy of the prediction. For example, the combination of Grey model GM $(1,1)$ with three-point moving average proposed by Professor Mao and Chirwa has been proven to be a more powerful forecasting tool and yields far much better predictions for vehicle fatality risk rates [15]. Its application to the UK and US data sets yields exact predictions that are of high repeatability with characteristics depicting high reliability and efficiency [16]. The paper is based on the Grey theory combined with the Verhulst model to predict nitrogen concentration which is the key factor of red tide. Traditional Verhulst model was put forward by Verhulst in the study of biological reproduction rules. The model is mainly used in large amount of data. Grey Verhulst model extends traditional Verhulst model so that it can be used in the unimodal type data.

In order to improve the accuracy of prediction, some researchers have optimized Grey Verhulst model. Evans proposed a Generalized Grey Verhulst model in which a new parameter estimation method was proposed on the basis of the relationship of background value and simulative function. The amount of British steel input was predicted by
Generalized Grey Verhulst model to prove its effectiveness [17]. Chunguang et al. established an unbiased Grey Verhulst model according to the objective function which is the minimum value of the square of subtraction between reciprocal accumulating generating sequence and its inversely simulative value [16]. Wang et al. established a new Grey Verhulst model and its application is put forward [18]. Julong improved the simulative accuracy by using Fourier transform to correct simulation residual, and the trend of the euro against the dollar was predicted by this model to prove the good forecasting effect [19]. According to the analysis of the existing Grey Verhulst models, there are few researches on the model from the perspective of the initial value and the simulative value.

In order to predict the nitrogen concentration in seawater and avoid the error accumulation problem, a new method to optimize the time response function of Grey Verhulst model is proposed according to the criterion of minimum sumsquare of difference between the raw data vector and the simulated data vector. The Logistic curve is used to fit the raw data, which optimizes background value and improves the prediction accuracy.

\section{The Optimization of the Grey Verhulst Model}

3.1. The Optimization of the Background Value. The Grey Verhulst model $\operatorname{GM}(1,1)$ is constituted by a first-order differential equation containing only one variable [20-22]. Assuming that $X^{(0)}$ is a nonnegative raw data sequence and that $X^{(1)}$ is an accumulative sequence of $X^{(0)}, X^{(1)}$ can be defined as follows [23-26]:

$$
\begin{aligned}
X^{(1)} & =\left\{x^{(1)}(1), x^{(1)}(2), \ldots, x^{(1)}(n)\right\}, \\
x^{(1)}(k) & =\sum_{j=1}^{k} x^{(0)}(j), \quad k=1,2, \ldots, n .
\end{aligned}
$$

In (1), $n$ is the number of data in the sequence.

The generated mean sequence $Z^{(1)}$ of $X^{(1)}$ is defined as

$$
\begin{aligned}
Z^{(1)} & =\left\{z^{(1)}(2), z^{(1)}(3), \ldots, z^{(1)}(n)\right\}, \\
z^{(1)}(k) & =0.5 x^{(1)}\left(t_{k}\right)+0.5 x^{(1)}\left(t_{k-1}\right), \quad k=2,3, \ldots, n .
\end{aligned}
$$

At this time, the power model of $\operatorname{GM}(1,1)$ is defined as follows:

$$
x^{(0)}(k)+a z^{(1)}(k)=b\left(z^{(1)}(k)\right)^{\alpha} .
$$

The whitening equation of $\operatorname{GM}(1,1)$ is defined as follows [27-30]:

$$
\frac{d x^{(1)}}{d t}+a x^{(1)}=b\left(x^{(1)}\right)^{\alpha} .
$$

When $\alpha=2$, according to (4), $X^{(1)}$ is calculated as [31-33]

$$
\hat{x}^{(1)}(k+1)=\frac{a x^{(1)}(1)}{b x^{(1)}(1)+\left(a-b x^{(1)}(1)\right) e^{a k}} .
$$


According to (5), $x^{(1)}(k)$ has S-type growth, which is shown in Figure 1 (the sequence of $x^{(1)}(k)$ is shown in Figure 1).

The integration results of $(4)$ in $(k-1, k)$ are shown as

$$
x^{(0)}(k)+a \int_{k-1}^{k} x^{(1)}(k) d t=b \int_{k-1}^{k} x^{(1)}(k)^{2} d t
$$

By comparison of (3) and (6), it can be seen that the definition equation of Grey Verhulst model uses the trapezoidal area to replace the curve graphics area. Therefore, the definition equation of Grey Verhulst model has the lower accuracy. Curve fitting method is proposed in this paper to fit raw data of the curve, and the background value and the accuracy of the model are improved by using (6) to solve the values of the parameters $a$ and $b$.

From (5) and Figure 1, Logistic curve is used to fit the raw data, and it can be expressed as

$$
x^{(1)}(k)=\frac{1}{p+q e^{m(k-1)}} .
$$

The weight function $e(t) \equiv 1$, so

$$
\frac{1}{x^{(1)}(k)}=p+q e^{m(k-1)}
$$

$$
\begin{aligned}
& p=\frac{1}{n} \sum_{k=1}^{n} \frac{1}{x^{(1)}(k)}-\frac{1}{n} \\
& \frac{\sum_{k=1}^{n}\left(1 / x^{(1)}(k)\right)\left(\sum_{k=2}^{n}\left(y^{(0)}(k) / y^{(0)}(k-1)\right)^{(k-1)}\right)^{2}-n \sum_{k=2}^{n}\left(1 / x^{(1)}(k)\right)\left(y^{(0)}(k) / y^{(0)}(k-1)\right)^{(k-1)} \sum_{k=2}^{n}\left(y^{(0)}(k) / y^{(0)}(k-1)\right)^{(k-1)}}{\left(\sum_{k=2}^{n}\left(y^{(0)}(k) / y^{(0)}(k-1)\right)^{(k-1)}\right)^{2}+n \sum_{k=2}^{n}\left(y^{(0)}(k) / y^{(0)}(k-1)\right)^{(2 k-2)}} \\
& z^{1}(k)=\int_{k-1}^{k} x^{(1)}(k) d t=-\frac{1}{m p} \ln \left|\frac{p e^{-m(k-1)}+q}{p e^{-m(k-2)}+q}\right| \\
& z^{2}(k)=\int_{k-1}^{k} x^{(1)}(k)^{2} d t \\
& =\frac{1}{m}\left[\frac{1}{p} \frac{q\left[e^{m(k-2)}-e^{m(k-1)}\right]}{\left(p+q e^{m(k-1)}\right)\left(p+q e^{m(k-2)}\right)}\right. \\
& \left.+\frac{1}{p^{2}} \ln \left|\frac{e^{m}\left(p+q e^{m(k-2)}\right)}{p+q e^{m(k-1)}}\right|\right]
\end{aligned}
$$$$
q=\frac{\sum_{k=1}^{n}\left(1 / x^{(1)}(k)\right) \sum_{k=2}^{n}\left(y^{(0)}(k) / y^{(0)}(k-1)\right)^{(k-1)}-n \sum_{k=2}^{n}\left(1 / x^{(1)}(k)\right)\left(y^{(0)}(k) / y^{(0)}(k-1)\right)^{(k-1)}}{\left(\sum_{k=2}^{n}\left(y^{(0)}(k) / y^{(0)}(k-1)\right)^{(k-1)}\right)^{2}+n \sum_{k=2}^{n}\left(y^{(0)}(k) / y^{(0)}(k-1)\right)^{(2 k-2)}} .
$$

Assume that

$$
\begin{aligned}
y^{(0)}(k) & =\frac{1}{x^{(1)}(k)}-\frac{1}{x^{(1)}(k+1)}, \\
\frac{y^{(0)}(k)}{y^{(0)}(k-1)} & =\frac{q e^{m(k-1)}\left(1-e^{m}\right)}{q e^{m(k-2)}\left(1-e^{m}\right)}=e^{m} .
\end{aligned}
$$

The parameter $m$ is calculated as follows:

$$
m=\ln \frac{y^{(0)}(k)}{y^{(0)}(k-1)} .
$$

According to (8), the parameters of $p, q$ are obtained by using the least squares approximation, which is shown as follows:

$$
\begin{aligned}
& n p+q \sum_{k=2}^{n}\left(\frac{y^{(0)}(k)}{y^{(0)}(k-1)}\right)^{(k-1)}-\sum_{k=1}^{n} \frac{1}{x^{(1)}(k)}=0 \\
& p \sum_{k=2}^{n}\left(\frac{y^{(0)}(k)}{y^{(0)}(k-1)}\right)^{(k-1)}-q \sum_{k=2}^{n}\left(\frac{y^{(0)}(k)}{y^{(0)}(k-1)}\right)^{(2 k-2)} \\
& -\sum_{k=2}^{n} \frac{1}{x^{(1)}(k)}\left(\frac{y^{(0)}(k)}{y^{(0)}(k-1)}\right)^{(k-1)}=0 .
\end{aligned}
$$

From (11), the solution of $p, q$ is shown as 


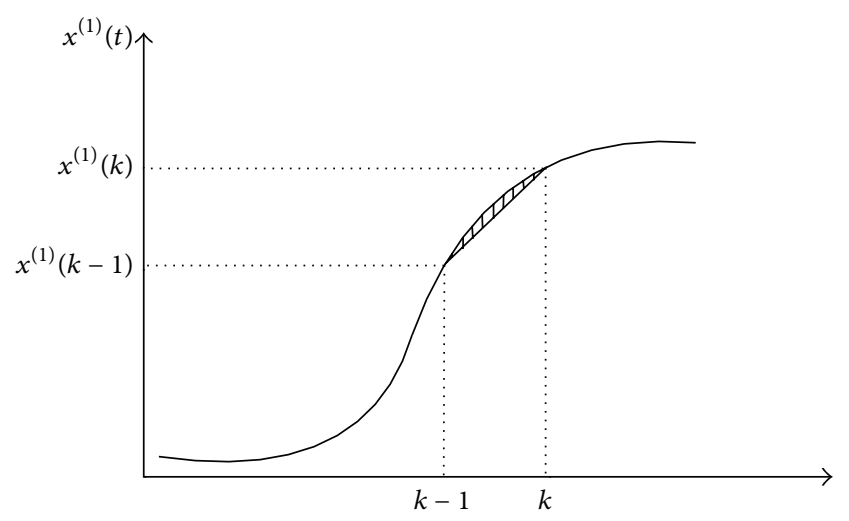

FIGURE 1: The trend graph of the accumulative sequence.

According to (14) and (15), the values of $a, b$ can be obtained with the results of optimized background value.

3.2. The Optimization of the Time Response. The general solution of (4) for the time response function is shown as

$$
\hat{x}^{(1)}(k)=\frac{1}{c e^{a k}+b / a} .
$$

By comparison of (16) and (5), the simulated curve passes by the first point of the raw data in the traditional solution, which does not necessarily fit the facts. The least squares method does not need the simulated curve to pass by the first point and the parameter $c$ can be solved according to the known information. According to the criterion of the minimum sum of square between the reciprocal of the raw data sequence and the reciprocal of the predictive value, the function $F(c)$ is defined as

$$
\begin{aligned}
F(c) & =\sum_{k=1}^{n}\left(c e^{a(k+1)}-c e^{a k}\right. \\
& \left.-\left(\frac{-x^{(0)}(k+1)}{\sum_{i=1}^{k+1} x^{(0)}(i) \sum_{i=1}^{k} x^{(0)}(i)}\right)\right)^{2} .
\end{aligned}
$$

According to the extreme conditions $F^{\prime}(c)=0$, the parameter $c$ can be calculated as

c

$$
=\frac{-\sum_{i=1}^{n}\left(x^{(0)}(k+1) / \sum_{i=1}^{k+1} x^{(0)}(i) \sum_{i=1}^{k} x^{(0)}(i)\right)\left(e^{a k}\left(e^{a}-1\right)\right)}{\sum_{i=1}^{n}\left(e^{a k}\left(e^{a}-1\right)\right)^{2}} .
$$

According to the above equation, the optimal general solution of time response function is obtained.

3.3. Grey Verhulst Model Accuracy Test. The accuracy of Grey Verhulst model can be tested by three methods: pretest, intermediate test, and post hoc test $[34,35]$. The posterior variance test method, which is a kind of intermediate test, is applied to test the accuracy of Grey Verhulst model. $\widehat{x}^{(0)}(n)$ is the predictive value, and the predictive sequence is shown as

$$
\widehat{X}^{(0)}=\left[\widehat{x}^{(0)}(1), \widehat{x}^{(0)}(2), \ldots, \widehat{x}^{(0)}(n)\right] .
$$

The residual is expressed as

$$
\begin{aligned}
E & =[e(1), e(2), \ldots, e(n)]=X^{(0)}-\widehat{X}^{(0)}, \\
e(k) & =x^{(0)}(k)-\widehat{x}^{(0)}(k), \quad k=1,2, \ldots, n .
\end{aligned}
$$

The variance of the raw sequence and residual sequence is shown as follows:

$$
\begin{aligned}
& S_{1}^{2}=\frac{1}{n} \sum_{k=1}^{n}\left[x^{(0)}(k)-\bar{x}\right]^{2}, \\
& S_{2}^{2}=\frac{1}{n} \sum_{k=1}^{n}[e(k)-\bar{e}]^{2} .
\end{aligned}
$$

In (21), $\bar{x}$ and $\bar{e}$ are defined as

$$
\begin{aligned}
& \bar{x}=\frac{1}{n} \sum_{k=1}^{n} x^{(0)}(k), \\
& \bar{e}=\frac{1}{n} \sum_{k=1}^{n} e(k) .
\end{aligned}
$$

The posterior variance ratio $C$ is defined as

$$
C=\frac{S_{2}}{S_{1}}
$$

The small error probability $p$ is defined as

$$
p=P\left\{|e(k)-\bar{e}|<0.6745 S_{1}\right\} .
$$

$C$ and $p$ are the two important indicators to validate the precision of the model. According to (24), $C$ is determined by $S_{2}$ and $S_{1}$. The bigger the value of $S_{1}$, the bigger the dispersion degree of the original data. A low value of $S_{2}$ indicates a low degree of residual dispersion. Therefore, $S_{2} / S_{1}$, namely, the value of $C$, being small shows that although the original data is very discrete, the relationship between the calculated values and the actual value of the model is not very discrete. $p$ indicates the number of dots of which the difference between the residual and the residual mean value is less than the given value, $0.0645 S_{1}$. The bigger the value of $p$ is, the more uniformly distributed is the fitted value. According to $C$ and $p$, the accuracy of the model can be divided into four levels, as shown in Table $1[36,37]$.

\section{Application Analysis of Optimal Grey Verhulst Model}

4.1. Example 1. As the Bohai Bay is a semiclosed harbor, it is not conducive for the pollutants to spread. The pollution of the sea water is very serious, which promotes the microbial growth. As a result, red tides often occur. The optimal Grey Verhulst model is applied to predict the nitrogen concentration in the Bohai Bay. The measured sample data of the nitrogen concentration in the Bohai Bay collected in summer is shown in Table 2. $x(k)$ refers to the nitrogen concentration in seawater on $k$ day. 
TABLE 1: Model accuracy grade table.

\begin{tabular}{lcc}
\hline The precision grade & $\begin{array}{c}\text { The posterior } \\
\text { variance ratio } C\end{array}$ & $\begin{array}{c}\text { Small error } \\
\text { probability } p\end{array}$ \\
\hline Level 1 (good) & $C \leq 0.35$ & $0.95 \leq p$ \\
Level 2 (qualified) & $0.35<C \leq 0.5$ & $0.80 \leq p<0.95$ \\
Level 3 (reluctant) & $0.5<C \leq 0.65$ & $0.70 \leq p<0.80$ \\
Level 4 (unqualified) & $0.65<C$ & $p<0.70$ \\
\hline
\end{tabular}

TABLE 2: The sample table of the nitrogen concentration with 9 sets.

\begin{tabular}{lc}
\hline Nitrogen samples & Concentration $(\mu \mathrm{mol} / \mathrm{L})$ \\
\hline$x(1)$ & 30 \\
$x(2)$ & 33 \\
$x(3)$ & 37 \\
$x(4)$ & 45 \\
$x(5)$ & 55 \\
$x(6)$ & 65 \\
$x(7)$ & 72 \\
$x(8)$ & 76 \\
$x(9)$ & 80 \\
\hline
\end{tabular}

Through the analysis of the measured raw data in Table 2, the sequence has been saturated. So the raw data are directly taken as the first-order accumulative data sequence $X^{(1)}$ which approximately matches the following Logistic function:

$$
x^{(1)}(k) \approx \frac{1}{0.0317 e^{-0.2661 k}+0.009}, \quad k=1,2, \ldots, n .
$$

The first eight sets of data in the sequence are taken as the modeling data which are used to establish the traditional Grey Verhulst model, the Grey Verhulst model based on optimal time response, and the Grey Verhulst model based on background value optimization, respectively. The last set of data in the sequence is used to make a comparison with prediction data in order to prove the extrapolation of the model.

In order to test the accuracy of different Grey models, various models are formed in this paper:

GVM: GVM $(1,1)$ model

TPGVM: Modified Grey Verhulst model at time response using the processed data [12]

BPGVM: Modified Grey Verhulst model at background value using the processed data [12]

TRGVM: Modified Grey Verhulst model at time response using the raw data

BRGVM: Modified Grey Verhulst model at background value using the raw data

GVM is shown as

$$
\begin{aligned}
& x^{(1)}(k+1)=\frac{7.983}{0.072+0.1914 e^{-0.2661 k}}, \\
& k=1,2, \ldots, n \text {. }
\end{aligned}
$$

TPGVM is shown as

$$
x^{(1)}(k)=\frac{0.2661}{0.0086 e^{-0.2661 k}+0.0024}, \quad k=1,2, \ldots, n .
$$

TRGVM is shown as

$$
x^{(1)}(k)=\frac{0.2661}{0.0093 e^{-0.2661 k}+0.0024}, \quad k=1,2, \ldots, n .
$$

Table 3 gives a comparison between the different Modified Grey Verhulst models at time response and the traditional Grey Verhulst model. The average relative error is the sum of absolute values of relative error. The extrapolated value is the model's predictive value.

The posterior variance ratio is calculated as

$$
\begin{aligned}
C & =\frac{S_{2}}{S_{1}}=0.130 \leq 0.35, \\
0.6745 S_{1} & =11.37 \\
|e(k)-\bar{e}| & <0.6745 S_{1} .
\end{aligned}
$$

So the small error probability $p=1$.

Although the average relative error results of three models are almost the same, Grey Verhulst model based on time response value optimization excludes different predictive models caused by different selection of raw data.

In the aspects of the extrapolation, shown as the last record in Table 3, TRGVM model is the best among three models, since the actual value is 80 .

Therefore, (28) can be used to make better predictions of the nitrogen concentration.

BPGVM is shown as

$$
\begin{aligned}
x^{(1)}(k+1)=\frac{7.953}{0.074+0.1911 e^{-0.2651 k}}, & \\
& k=1,2, \ldots, n .
\end{aligned}
$$

BRGVM is shown as

$$
\begin{aligned}
& x^{(1)}(k+1)=\frac{8.296}{0.078+0.2068 e^{-0.2673 k}} \text {, } \\
& k=1,2, \ldots, n \text {. }
\end{aligned}
$$

Table 4 gives a comparison between the different Modified Grey Verhulst models at background value and the traditional Grey Verhulst model.

The posterior variance ratio is shown as

$$
\begin{aligned}
C & =\frac{S_{2}}{S_{1}}=0.003 \leq 0.35, \\
0.6745 S_{1} & =11.37 \\
|e(k)-\bar{e}| & <0.6745 S_{1} .
\end{aligned}
$$

So the small error probability $p=1$.

In the aspects of the extrapolation, shown as the last record in Table 4, BRGVM model is also the best among three models, since the actual value is 80 .

Therefore, (31) can be used to make better predictions of the nitrogen concentration. 
TABLE 3: Accuracy comparison of GVM, TPGVM, and TRGVM models.

\begin{tabular}{|c|c|c|c|c|c|c|}
\hline \multirow{2}{*}{$\begin{array}{l}\text { Measured } \\
\text { raw data }\end{array}$} & \multicolumn{2}{|c|}{ GVM } & \multicolumn{2}{|c|}{ TPGVM } & \multicolumn{2}{|c|}{ TRGVM } \\
\hline & Prediction value & The relative error $(\%)$ & Prediction value & The relative error $(\%)$ & Prediction value & The relative error $(\%)$ \\
\hline 30 & 30 & 0 & 29.9 & -0.5 & 27.9 & -6.9 \\
\hline 33 & 36.5 & 10.6 & 35.9 & 9.1 & 33.8 & 2.5 \\
\hline 37 & 43.2 & 16.9 & 42.7 & 15.5 & 40.4 & 9.2 \\
\hline 45 & 50.5 & 12.1 & 49.9 & 10.9 & 47.5 & 5.4 \\
\hline 55 & 57.8 & 5.1 & 57.2 & 4.1 & 54.7 & -0.4 \\
\hline 65 & 65.1 & 0.2 & 64.6 & -0.7 & 62.1 & -4.4 \\
\hline 72 & 72.1 & 0.09 & 71.5 & -0.6 & 69.2 & -3.9 \\
\hline 76 & 78.4 & 3.3 & 78.0 & 2.6 & 75.9 & -0.1 \\
\hline $\begin{array}{l}\text { Average } \\
\text { relative error } \\
(\%)\end{array}$ & & 6.9 & & 5.5 & & 4.1 \\
\hline $\begin{array}{l}\text { Extrapolation } \\
\text { values }\end{array}$ & & 84.2 & & 83.6 & & 81.9 \\
\hline
\end{tabular}

TABLE 4: Accuracy comparison of GVM, BPGVM, and BRGVM models.

\begin{tabular}{|c|c|c|c|c|c|c|}
\hline \multirow{2}{*}{$\begin{array}{l}\text { Measured } \\
\text { raw data }\end{array}$} & \multicolumn{2}{|c|}{ GVM } & \multicolumn{2}{|c|}{ BPGVM } & \multicolumn{2}{|c|}{ BRGVM } \\
\hline & Prediction value & The relative error $(\%)$ & Prediction value & The relative error $(\%)$ & Prediction value & The relative error (\%) \\
\hline 30 & 30 & 0 & 30 & 0 & 29.1 & -2.9 \\
\hline 33 & 36.5 & 10.6 & 36.1 & 9.2 & 35.1 & 6.3 \\
\hline 37 & 43.2 & 16.9 & 42.7 & 15.3 & 41.7 & 12.5 \\
\hline 45 & 50.5 & 12.1 & 49.6 & 10.2 & 48.5 & 7.9 \\
\hline 55 & 57.8 & 5.1 & 56.7 & 3.1 & 55.6 & 1.2 \\
\hline 65 & 65.1 & 0.2 & 63.7 & -1.9 & 62.7 & -3.5 \\
\hline 72 & 72.1 & 0.09 & 70.4 & -2.2 & 69.4 & -3.6 \\
\hline 76 & 78.4 & 3.3 & 76.5 & 0.7 & 75.5 & 0.0 \\
\hline $\begin{array}{l}\text { Average } \\
\text { relative error } \\
(\%)\end{array}$ & & 6.9 & & 5.3 & & 4.8 \\
\hline $\begin{array}{l}\text { Extrapolation } \\
\text { values }\end{array}$ & & 84.2 & & 82.0 & & 81.0 \\
\hline
\end{tabular}

4.2. Example 2. In order to further illustrate the advantages of the proposed optimization model, the sample data is increased in this example. The 18 sets of the nitrogen concentration in Zhuhai estuary collected in summer are shown in Table 5. The last two sets of data are extrapolated data. The comparison between the different Modified Grey Verhulst models and the traditional Grey Verhulst model is shown in Tables 6 and 7.

According to Tables 6 and 7, the Modified Grey Verhulst model using the raw data is the best model in contrast with the Modified Grey Verhulst model using the processed data and the traditional Grey Verhulst model because it has the best prediction and extrapolation effect.

\section{Conclusion}

After analyzing the trends of the nitrogen concentration which is the key factor in red tide occurrence, an optimal Grey Verhulst model is proposed to predict the nitrogen concentration in seawater. In order to improve the predictive accuracy, two optimal methods are put forward: the optimization of the background value and the time response. The application results show that the optimal Grey Verhulst
TABLE 5: The sample table of the nitrogen concentration with 18 sets.

\begin{tabular}{lc}
\hline Nitrogen samples & Concentration $(\mu \mathrm{mol} / \mathrm{L})$ \\
\hline$x(1)$ & 28 \\
$x(2)$ & 30 \\
$x(3)$ & 32 \\
$x(4)$ & 35 \\
$x(5)$ & 36 \\
$x(6)$ & 42 \\
$x(7)$ & 46 \\
$x(8)$ & 51 \\
$x(9)$ & 57 \\
$x(10)$ & 65 \\
$x(11)$ & 74 \\
$x(12)$ & 83 \\
$x(13)$ & 90 \\
$x(14)$ & 95 \\
$x(15)$ & 99 \\
$x(16)$ & 102 \\
$x(17)$ & 100 \\
$x(18)$ & 101 \\
\hline
\end{tabular}

model can better forecast the trends of the nitrogen concentration than the other two methods. Since the optimal Grey 
TABLE 6: Accuracy comparison of GVM, TPGVM, and TRGVM models.

\begin{tabular}{|c|c|c|c|c|c|c|}
\hline \multirow{2}{*}{$\begin{array}{l}\text { Measured } \\
\text { raw data }\end{array}$} & \multicolumn{2}{|r|}{ GVM } & \multicolumn{2}{|c|}{ TPGVM } & \multicolumn{2}{|c|}{ TRGVM } \\
\hline & Prediction value & The relative error $(\%)$ & Prediction value & The relative error $(\%)$ & Prediction value & The relative error (\%) \\
\hline 28 & 28 & 0 & 27.3 & -2.5 & 26.1 & -6.8 \\
\hline 30 & 33.4 & 11.3 & 33.5 & 11.6 & 33.8 & 12.7 \\
\hline 32 & 39.2 & 22.5 & 38.2 & 19 & 34.8 & 8.8 \\
\hline 35 & 41.3 & 18 & 41.3 & 18 & 40.7 & 16 \\
\hline 36 & 43.5 & 17.5 & 42.2 & 14.1 & 39.2 & 6.0 \\
\hline 42 & 44.5 & 5.9 & 43.9 & 4.5 & 42.2 & 0.5 \\
\hline 46 & 48.8 & 6.1 & 45.3 & -1.5 & 44.9 & -2.4 \\
\hline 51 & 53.6 & 5.1 & 52.8 & 3.5 & 53.2 & 4.3 \\
\hline 57 & 60.3 & 5.8 & 60.2 & 5.6 & 58.9 & 3.3 \\
\hline 65 & 67.6 & 4 & 68.1 & 4.7 & 66.7 & 2.6 \\
\hline 74 & 77.8 & 5.1 & 72.6 & -1.9 & 75.6 & 2.2 \\
\hline 83 & 85.9 & 3.5 & 85.3 & 2.8 & 83.5 & 0.6 \\
\hline 90 & 93.6 & 4 & 92.5 & 2.8 & 92.1 & 2.3 \\
\hline 95 & 98.5 & 3.7 & 97.2 & 2.3 & 96.3 & 1.3 \\
\hline 99 & 100.7 & 1.7 & 101.1 & 2.1 & 100.5 & 1.5 \\
\hline 102 & 103.2 & 1.1 & 102.7 & 0.7 & 101.4 & 0.6 \\
\hline $\begin{array}{l}\text { Average } \\
\text { relative error } \\
(\%) \\
\end{array}$ & \multicolumn{2}{|r|}{7.2} & \multicolumn{2}{|r|}{5.3} & \multicolumn{2}{|r|}{3.3} \\
\hline \multirow{2}{*}{$\begin{array}{l}\text { Extrapolation } \\
\text { values }\end{array}$} & \multicolumn{2}{|r|}{104.2} & \multicolumn{2}{|r|}{102.2} & \multicolumn{2}{|r|}{101.5} \\
\hline & \multicolumn{2}{|r|}{104.7} & \multicolumn{2}{|r|}{103.8} & \multicolumn{2}{|r|}{102.1} \\
\hline
\end{tabular}

TABLE 7: Accuracy comparison of GVM, BPGVM, and BRGVM models.

\begin{tabular}{|c|c|c|c|c|c|c|}
\hline \multirow{2}{*}{$\begin{array}{l}\text { Measured } \\
\text { raw data }\end{array}$} & \multicolumn{2}{|r|}{ GVM } & \multicolumn{2}{|c|}{ BPGVM } & \multicolumn{2}{|c|}{ BRGVM } \\
\hline & Prediction value & The relative error (\%) & Prediction value & The relative error (\%) & Prediction value & The relative error (\%) \\
\hline 28 & 28 & 0 & 27.2 & -3.6 & 26.3 & -7.1 \\
\hline 30 & 33.4 & 11.3 & 33.1 & 10.3 & 33.6 & 12 \\
\hline 32 & 39.2 & 22.5 & 38.7 & 20.9 & 35.4 & 10.6 \\
\hline 35 & 41.3 & 18 & 40.7 & 16.2 & 40.5 & 15.7 \\
\hline 36 & 43.5 & 17.5 & 42.7 & 15.4 & 40.9 & 9.4 \\
\hline 42 & 44.5 & 5.9 & 43.5 & 3.6 & 42.6 & 1.4 \\
\hline 46 & 48.8 & 6.1 & 44.7 & -2.8 & 45.5 & -1.1 \\
\hline 51 & 53.6 & 5.1 & 53.3 & 4.5 & 52.2 & 2.3 \\
\hline 57 & 60.3 & 5.8 & 60.5 & 6.1 & 59.4 & 4.2 \\
\hline 65 & 67.6 & 4 & 67.2 & 3.3 & 66.5 & 2.3 \\
\hline 74 & 77.8 & 5.1 & 73.1 & 1.2 & 75.3 & 1.8 \\
\hline 83 & 85.9 & 3.5 & 86.1 & 3.7 & 84.8 & 2.1 \\
\hline 90 & 93.6 & 4 & 93.2 & 3.4 & 92.3 & 2.6 \\
\hline 95 & 98.5 & 3.7 & 97.6 & 2.7 & 96.7 & 1.8 \\
\hline 99 & 100.7 & 1.7 & 101.3 & 2.3 & 100.3 & 1.3 \\
\hline 102 & 103.2 & 1.1 & 102.4 & 0.4 & 102.5 & 0.5 \\
\hline $\begin{array}{l}\text { Average } \\
\text { relative error } \\
(\%) \\
\end{array}$ & \multicolumn{2}{|r|}{7.2} & \multicolumn{2}{|r|}{5.4} & \multicolumn{2}{|r|}{3.8} \\
\hline \multirow{2}{*}{$\begin{array}{l}\text { Extrapolation } \\
\text { values }\end{array}$} & \multicolumn{2}{|r|}{104.7} & \multicolumn{2}{|r|}{103.3} & \multicolumn{2}{|r|}{102.4} \\
\hline & \multicolumn{2}{|r|}{103.6} & \multicolumn{2}{|r|}{103.1} & \multicolumn{2}{|r|}{102.2} \\
\hline
\end{tabular}


Verhulst model is only suitable for S-type data, combining the optimal Grey Verhulst model with other algorithms to overcome the defects in the optimal Grey Verhulst model will be the focus of study in the future.

\section{Notations}

GM: $\quad$ Grey dynamic model

GVM: Grey Verhulst model

TPGVM: Modified Grey Verhulst model at time response using the processed data

BPGVM: Modified Grey Verhulst model at background value using the processed data

TRGVM: Modified Grey Verhulst model at time response using the raw data

BRGVM: Modified Grey Verhulst model at background value using the raw data

$X^{(0)}$ : $\quad$ Nonnegative raw data sequence

$X^{(1)}$ : $\quad$ Accumulative sequence of $X^{(0)}$

$X^{(c)}$ : Accumulative sequence

$n$ : $\quad$ Number of data in the sequence

$Z^{(1)}$ : $\quad$ Generated mean sequence

$e(t)$ : Weight function

$\widehat{X}^{(0)}$ : $\quad$ Predictive value

$(a, b)^{T}: \quad$ Sequence of parameters

$E$ : $\quad$ Residual

$S^{2}$ : $\quad$ Variance of the raw sequence and residual sequence

C: $\quad$ Posterior variance ratio

$P$ : $\quad$ Small error probability.

\section{Competing Interests}

The authors declare that there are no competing interests regarding the publication of this article.

\section{Acknowledgments}

This work was supported by the Grand Science \& Technology Program Shanghai China (no. 16111105900).

\section{References}

[1] Y. Luo, X. Liu, R. S. Wu, and Y. J. Wu, "System construction improvement of the ability of marine disaster prevention," Applied Mechanics and Materials, vol. 522, pp. 501-504, 2014.

[2] R. E. Sipler, D. A. Bronk, S. P. Seitzinger et al., "Trichodesmiumderived dissolved organic matter is a source of nitrogen capable of supporting the growth of toxic red tide Karenia brevis," Marine Ecology Progress Series, vol. 483, pp. 31-45, 2013.

[3] L. Sifeng, G. Tianbang, D. Yaoguo et al., The Grey System Theory and Its Application, Science Press, Beijing, China, 1999.

[4] D. Julong, Grey System Method, Huazhong University of Science and Technology Press, Wuhan, China, 1987.

[5] X. Xinping and Q. Lifen, "A new type solution and bifurcation of grey Verhulst model," Journal of Grey System, vol. 24, no. 2, pp. 165-174, 2012.
[6] D. Julong, Grey System Theory, Huazhong University of Science and Technology Press, Wuhan, China, 2002.

[7] C. Cuiwen and G. Xingsheng, "The application of the metabolism of grey dynamic model in the product price forecasting and demand forecasting," Information and Control, vol. 34, no. 8, pp. 398-402, 2005.

[8] N. Xie, C. Zhu, S. Liu, and Y. Yang, "On discrete grey system forecasting model corresponding with polynomial time-vary sequence," Journal of Grey System, vol. 25, no. 4, pp. 1-18, 2013.

[9] S. Yanhui and N. Dexin, "Grey Verhulst model of the foundation settlement prediction," Rock and Soil Mechanics, vol. 24, no. 1, pp. 123-126, 2003.

[10] J. Ming, Z. Fan, Z. Xie, Y. Jiang, and B. Zuo, "A modified grey verhulst model method to predict ultraviolet protection performance of aging B.mori silk fabric," Fibers and Polymers, vol. 14, no. 7, pp. 1179-1183, 2013.

[11] L. Yucheng, "The improved Verhulst model of the building settlement," Chinese Journal of Geological Hazard and Control, vol. 17, no. 4, pp. 61-63, 2006.

[12] X. Pingping, The optimization method the grey MGM $(1, m)$ and Verhulst model [M.S. thesis], Nanjing University of Aeronautics \& Astronautics, Nanjing, China, 2012.

[13] W. Hongli and F. Jianfeng, Ecological Dynamics and Prediction of the Red Tides, Tianjin University Press, 2006.

[14] F. Shizhai, L. Fengqi, and L. Shaozhu, An Introduction to Marine Science, Higher Education Press, Beijing, China, 1999.

[15] M. Mao and E. C. Chirwa, "Application of grey model GM(1,1) to vehicle fatality risk estimation," Journal of Technological Forecasting \& Social Change, vol. 73, no. 5, pp. 588-605, 2006.

[16] S. Chunguang, C. Wanming, and P. Lingling, "The optimization of the initial conditions of unbiased Grey Verhulst model," Statistics and Information BBS, vol. 26, no. 5, pp. 3-6, 2011.

[17] M. Evans, "An alternative approach to estimating the parameters of a generalised grey verhulst model: an application to steel intensity of use in the UK," Expert Systems with Applications, vol. 41, no. 4, pp. 1236-1244, 2014.

[18] Z. Wang, Y. Dang, and Y. Wang, "A new grey Verhulst model and its application," in Proceedings of the IEEE International Conference on Grey Systems and Intelligent Services (GSIS '07), pp. 571-574, Nanjing, China, November 2007.

[19] D. Julong, "On judging the admissibility of grey modeling via class ratio," The Journal of Grey System, no. 4, p. 249, 1993.

[20] F. Zhang, F. Liu, W. Zhao et al., "Application of grey verhulst model in middle and long term load forcasting," Power System Technology, vol. 5, article 8, 2003.

[21] Z. Gou, X. Song, and J. Ye, "A Verhulst model on time series error corrected for port throughput forecasting," Journal of the Eastern Asia Society for Transportation Studies, vol. 6, pp. 881891, 2005.

[22] K.-L. Wen and Y.-F. Huang, "The development of Grey Verhulst toolbox and the analysis of population saturation state in Taiwan-Fukien," in Proceedings of the IEEE International Conference on Systems, Man and Cybernetics (SMC '04), vol. 6, pp. 5007-5012, IEEE, October 2004.

[23] D. Julong, Grey Prediction and Grey Decision Making, Huazhong University of Science and Technology Press, Wuhan, China, 2000.

[24] D. Julong and G. Hong, Method and Application of Grey Forecasting Model, High Book Company, 1999.

[25] L. Chen and L. Zhang, "Combination grey verhulst model based on initial value modification," Mathematics in Practice and Theory, vol. 11, article 26, 2010. 
[26] W. Liu and W. A. Xu, "A new algorithm for estimating parameters of grey verhulst model," Computer Simulation, vol. 11, pp. 119-123, 2008.

[27] J. Xu, T. Tan, M. Tu, and L. Qi, "Improvement of grey models by least squares," Expert Systems with Applications, vol. 38, no. 11, pp. 13961-13966, 2011.

[28] W. Zhixin, D. Yaoguo, and S. Chunguang, "The research of the improvement of the Grey Verhulst derivative model," Statistics and Information BBS, no. 6, pp. 19-22, 2010.

[29] X. Kaigui, H. Bin, Z. Jiming et al., "The discussion of the modeling method of Grey forecasting model," Journal of Chongqing Institute of Post and Telecommunications, no. 3, pp. 56-60, 1998.

[30] C. Fangqiang, T. Fan, and J. Yonggang, "The application of Verhulst model in the prediction of the soft ground settlement of embankment," Journal of Rock Mechanics and Engineering, vol. 26, no. 7, pp. 3122-3126, 2007.

[31] Q. Li, "Application of grey Verhulst model to commercial flights at the Macau International Airport," in Proceedings of the 24th IEEE International Conference on Grey Systems and Intelligent Services (GSIS '13), pp. 161-163, November 2013.

[32] E. Kayacan, B. Ulutas, and O. Kaynak, "Grey system theorybased models in time series prediction," Expert Systems with Applications, vol. 37, no. 2, pp. 1784-1789, 2010.

[33] T. C. Lin, F. P. Hsu, and B. Y. Chen, "Comparing accuracy of $\operatorname{GM}(1,1)$ and grey Verhulst model in Taiwan dental clinics forecasting," The Journal of Grey System, vol. 19, no. 1, pp. 31-38, 2007.

[34] Z.-X. Wang, Y.-G. Dang, and S.-F. Liu, "Unbiased grey Verhulst model and its application," Systems Engineering-Theory \& Practice, vol. 29, no. 10, pp. 138-144, 2009.

[35] H. Wenzhang and W. Aidi, "The method and application of the estimated Verhulst model parameters in the linear programming," Systems Engineering Theory and Practice, vol. 26, no. 8, pp. 141-144, 2006.

[36] G.-D. Li, D. Yamaguchi, and M. Nagai, "The development of stock exchange simulation prediction modeling by a hybrid grey dynamic model," The International Journal of Advanced Manufacturing Technology, vol. 36, no. 1, pp. 195-204, 2008.

[37] L.-C. Hsu, "Applying the Grey prediction model to the global integrated circuit industry," Technological Forecasting and Social Change, vol. 70, no. 6, pp. 563-574, 2003. 


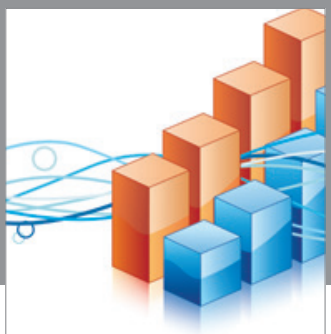

Advances in

Operations Research

vatem alat4

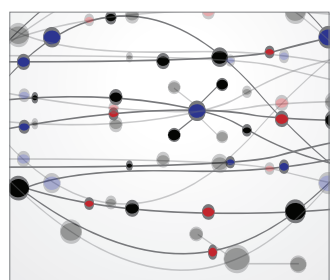

\section{The Scientific} World Journal
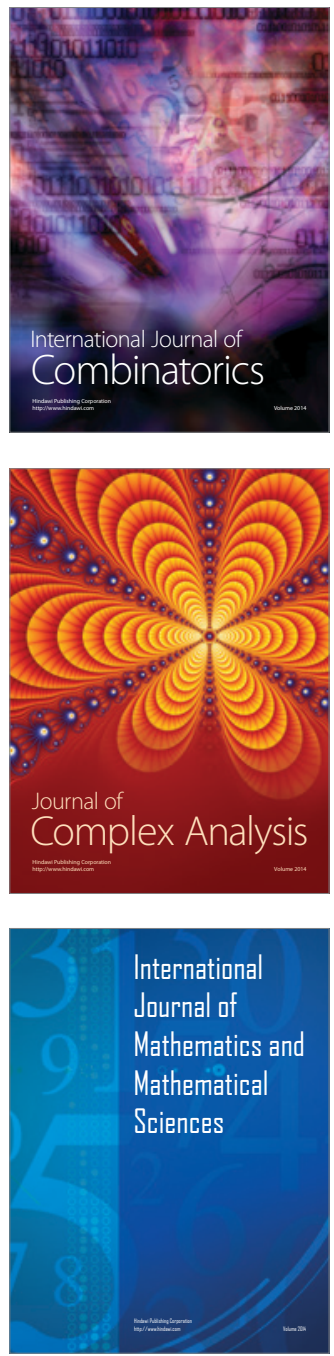
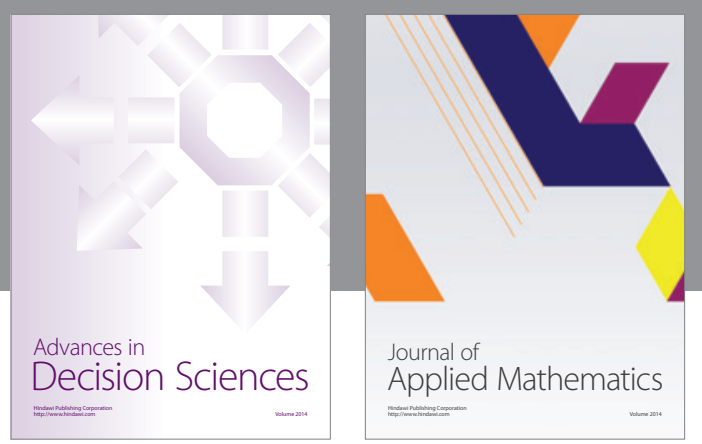

Algebra

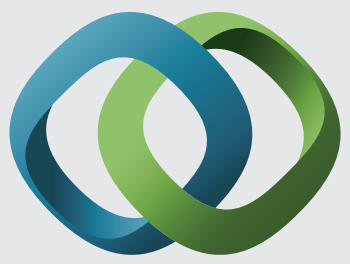

\section{Hindawi}

Submit your manuscripts at

http://www.hindawi.com
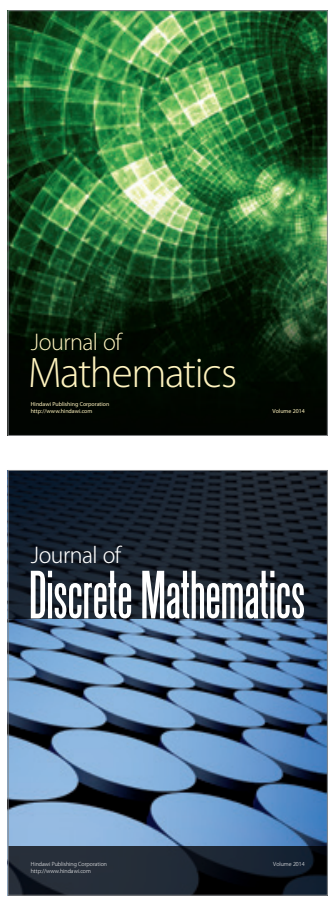

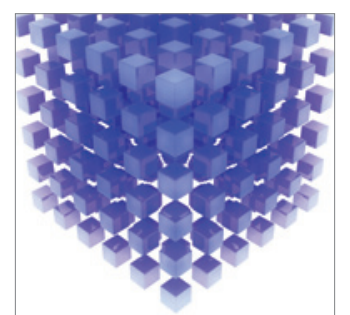

Mathematical Problems in Engineering
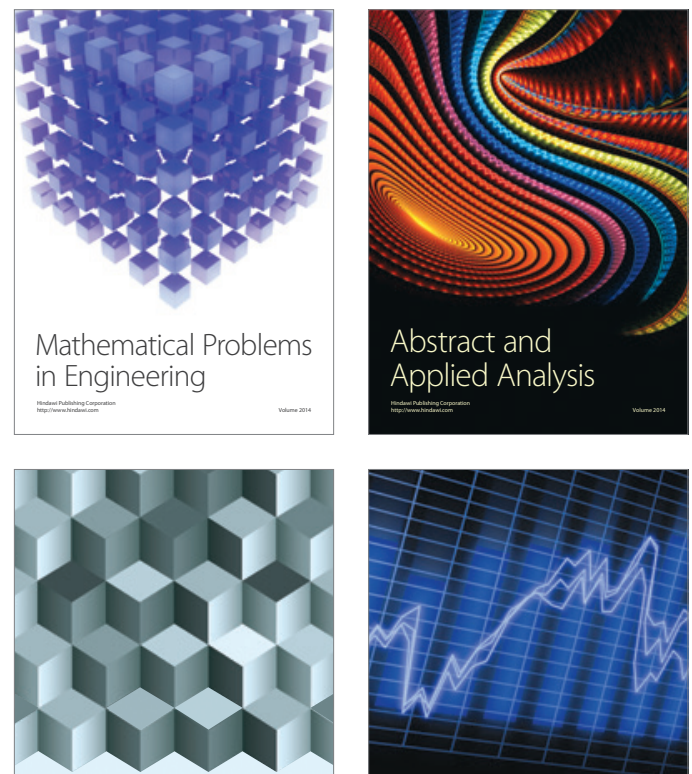

Journal of

Function Spaces

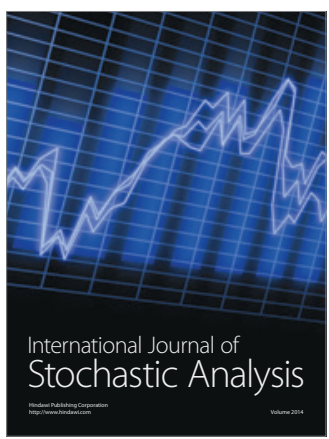

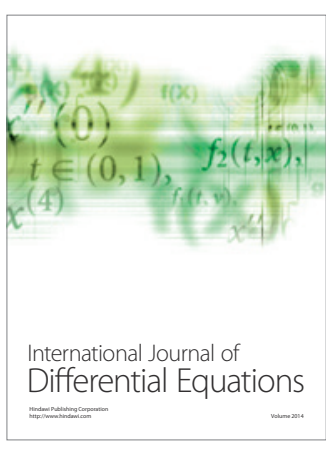
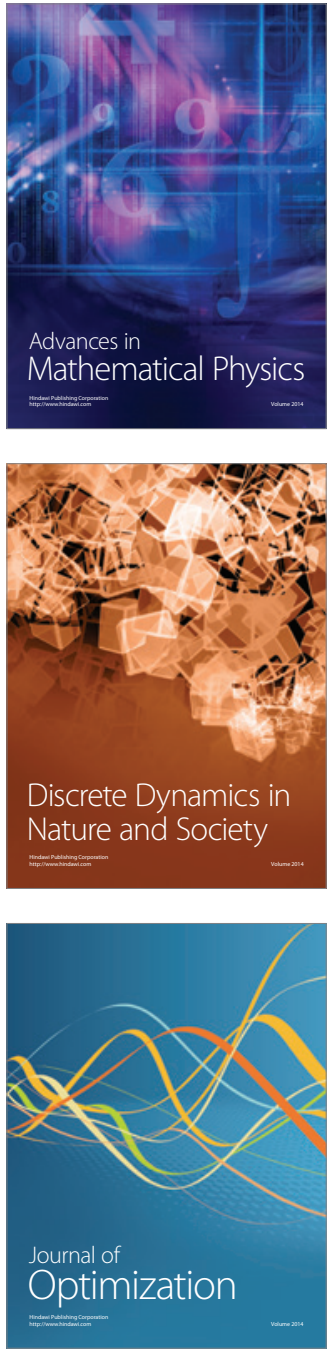